\title{
Floods in Pakistan: a public health crisis
}

\author{
Haider Warraich, ${ }^{a}$ Anita KM Zaidi ${ }^{b}$ \& Kavita Patel ${ }^{c}$
}

\section{Background}

In August 2010, Pakistan experienced floods that affected 20 million people in 78 districts, killed 1800, damaged or destroyed about 2 million homes, 514 health facilities and inundated a land mass the size of England. ${ }^{1}$ Prior to this current crisis, Pakistan already had about four million internally displaced people and refugees due to the war along the Afghan border and the 2005 earthquake in Khyber-Pakhtunkhwa (formerly North-West Frontier Province). Health indicators in Pakistan were dismal even before the floods, with maternal mortality at 230 (190-280) per 100000 live births and under-5 mortality at 89 per 1000 live births. ${ }^{2}$ Most of the flooded populations comprise the lowest socioeconomic quintiles that were already facing neglect. This crisis has worsened their plight.

\section{Relief agencies}

Relief operations were mainly carried out by the Pakistani government, the army and international agencies such as the World Health Organization (WHO), the United Nations Children's Fund (UNI$\mathrm{CEF})$, Médecins Sans Frontières and the United States Agency for International Development (USAID). ${ }^{3}$ In addition, civilian volunteers, independent teams of physicians, nongovernmental organizations and various other groups with little experience in disaster relief were also working in the field. The Pakistan army provided the most visible rescue operations but was overextended with massive rescue efforts, shoring up and breaching dykes, as well as fighting the war in the tribal areas. The National Disaster Management Authority was established after the earthquake in 2005. However, it does not have a dedicated post for an individual overseeing the public health aspect of the disaster. Widespread mistrust of governmental agencies, primarily stemming from perceived corruption and mismanagement, has hindered donors and citizens from cooperating with governmental initiatives. We strongly recommend that the government take the lead in coordinating the public health response and allocate personnel and resources to that effect.

\section{Infectious diseases}

Between August and September 2010, 6.2 million consultations for gastroenteritis, respiratory infections, malaria and dermatologic conditions were reported to WHO from 50 of 64 affected districts, with countless more predicted to fall sick in the period that followed. ${ }^{1}$ Using surveillance data from flood-affected districts, WHO reported mounting cases of Crimean-Congo haemorrhagic fever, dengue fever, cholera, falciparum malaria, measles and polio. ${ }^{3}$ A nationwide diphtheria outbreak was also unfolding at the time of writing this paper. An oral cholera vaccine is available and recommended for use in humanitarian emergencies by $\mathrm{WHO}^{4}$ yet it has not been recommended for use in flood-affected areas due to perceived logistic difficulties in delivery, e.g. twodose regimen, vaccine production capacity. While such obstacles were overcome for delivery of the $\mathrm{H} 1 \mathrm{~N} 1$ pandemic $\mathrm{flu}$ vaccine, mass cholera vaccination was not given priority in Pakistan. With the manufacture and potential availability of a cheap and effective cholera vaccine from India, mass vaccination may have been a consideration for the affected populations in Pakistan.

Adverse impact on polio eradication has been significant. Pakistan is one of only four countries where polio remains endemic. Eradication remains a challenge due to the complex situation exacerbated by the war in Afghanistan, insurgency in Pakistan and the resulting mass movement of people. By 9 November 2010, Pakistan accounted for about 62\% (111 cases) of all 180 polio cases from endemic countries, ${ }^{5}$ and most new cases were from flood-affected areas. ${ }^{3}$ However, WHO increased efforts at delivering vaccination services in 45 flood-affected districts and, due to enhanced cooperation between the Pakistan Expanded Program on Immunization (EPI), WHO and UNICEF, national immunization days went ahead as planned. ${ }^{3}$

Our first-hand experience from multiple camps set up by the Aga Khan University revealed that diarrhoeal illnesses were rampant due to a lack of safe drinking water. In Khairpur, Sindh, paediatricians and nurses from the Aga Khan University managed almost 500 severely dehydrated children in one week (Anita KM Zaidi, personal communication, 2010). The majority of those living in makeshift camps were women and children, who were at great risk of disease due to pre-existing malnutrition, lack of safe drinking water and an unhygienic environment. Most of the men had left their families in the camps to search for food and/or temporary employment. These camps were teeming with sick contacts, livestock and vectors such as mosquitoes, rodents and contaminated food and water. Lack of appropriate expertise for newborn care was particularly evident. Several cases of measles encephalitis, neonatal tetanus and heat stroke were reported.

\section{Recommendations}

Considering the vast areas involved, surveillance is of paramount importance to promptly identify disease outbreaks, food and supply shortages, and the nutritional status of affected populations. Early disease outbreak surveillance has been commendable in this crisis. Use of geographic information systems software such as Google Earth can be particularly effective in such large-scale settings. ${ }^{6}$ They should be used to target interventions where there is high disease incidence and vulnerable groups such as

\footnotetext{
a Beth Israel Deaconess Medical Center, Harvard Medical School, Boston, MA, United States of America (USA).

${ }^{\mathrm{b}}$ Department of Paediatrics and Child Health, Aga Khan University, Karachi, Pakistan.

${ }^{c}$ Health Policy Program, New America Foundation, Washington, DC, USA.

Correspondence to Haider Warraich (e-mail: hwarraic@bidmc.harvard.edu).

(Submitted: 6 October 2010 - Revised version received: 23 November 2010 -Accepted: 7 December 2010)
} 
pregnant women, newborns, disabled and elderly people.

Evidence-based strategies known to save lives in such complex emergencies need to be implemented by field operators and policy-makers. WHO's handbook Communicable disease control in emergencies: a field manual includes measures that can be taken to minimize the risk of infectious diseases in complex emergencies. The Cochrane Library has made available water-safety and water-related disease reviews for development of appropriate guidelines, free for Pakistani users (available at: http://www.thecochranelibrary.com/details/collection/814673/ Cochrane-Evidence-Aid-resources-forflooding-and-poor-water-sanitation. html). Additionally, the Sphere Project has published a free Urdu version of the Sphere humanitarian charter and minimum standards in disaster response that contains detailed chapters on various precautions to be applied in disaster settings, including water, sanitation and hygiene promotion, shelter, settlements and non-food items (available at: http:// www.sphereproject.org/).

Preventing infectious disease transmission should be the main focus of relief efforts. Adequate hygiene and sanitation are of primary importance in diarrhoeal disease prevention. Flood victims need safe water and information about the benefits of maintaining hygienic practices, such as hand washing with soap, exclusive breast-feeding for the first 6 months and disposal of human excreta to curtail disease transmission. ${ }^{3}$ Mass vaccination for children against measles and cholera is particularly important.
Mental health is an oft-ignored aspect of disaster relief efforts, though prevalence of post-traumatic stress disorder and depression is very high in flooded populations ${ }^{7}$ and can be an impediment to rehabilitation. Community workers in Pakistan have previously been successfully trained to deliver psychosocial interventions $^{8}$ and must be employed to cater to those affected by the floods.

International economic aid has been slow in proportion to the scale of the disaster. Possible reasons include donor fatigue, the global economic recession, lesser perceived impact of the floods, fear of fund embezzlement, Pakistan's negative image and association with terrorism and fear of terrorist attacks on aid workers. Thus, safety of aid workers should be made a top priority by the government. Another concrete step would be for the government to make financial disclosures and resource allocation available for viewing on the Internet as a means to increase transparency and donor confidence.

Public-private partnerships define the modern international health and development landscape. ${ }^{9}$ Close alignment of values and interests between public and private public-health entities, as well as the recipient countries, is critical to the initial surge effort as well as for post-crisis efforts.

While aid can provide short-term support, increasing governmental revenue collection is the only effective long-term means to provide the economic support required to rehabilitate the flooded populations. Thus, there is a need for broad economic and tax reform, including in- creasing taxation of the higher socioeconomic classes such as the agricultural elite.

\section{Future prospects}

While the disaster might have receded from the global spotlight, the public health challenge is mounting. Large populations have been displaced from their homes and their livelihoods have been destroyed. Great impetus is required to sustain existing public health interventions such as vaccination, education and nutritional education, female health worker and trained birth attendant programmes. Furthermore, the winter season was expected to increase food insecurity, malnutrition and the prevalence of diseases such as malaria and pneumonia. ${ }^{1}$

Long-standing issues need to be addressed. National consensus is necessary to overcome challenges faced by a mobile population composed of ethnically diverse groups. Villagers need to be permanently resettled away from flood-prone riverbeds. Changing weather patterns brought about by climate change need to be examined with even greater urgency. This is a time for some much-needed collective introspection and collaboration. Global actors must advocate for the victims of these floods to prevent this massive humanitarian crisis from worsening. Furthermore, they must persuade the Pakistani government to increase transparency and initiate far-reaching reform that will reduce its dependence on foreign aid.

Competing interests: None declared.

\section{References}

1. Pakistan Health Cluster - Floods in Pakistan. (No. 19, Focus on donors, 28 September 2010). Cairo: World Health Organization Regional Office for the Eastern Mediterranean; 2010.

2. Global Health Observatory - Pakistan 1990-2008. Geneva: World Health Organization; 2010. Available from: http://apps. who.int/ghodata/?vid=15300 [accessed on 20 January 2011].

3. Pakistan Health Cluster - Floods in Pakistan. (No.20, 12 October 2010). Cairo: World Health Organization Regional Office for the Eastern Mediterranean; 2010

4. Cholera vaccines. Wkly Epidemiol Rec 2001;76:117-24. PMID:11338983

5. Monthly situation report: October/November 2010. Geneva: Global Polio Eradication Initiative; 2010. Available from: http://www.polioeradication.org/ Mediaroom/Monthlysituationreports/2010/OctoberNovember.aspx [accessed on 20 January 2011]
6. Lozano-Fuentes S, Elizondo-Quiroga D, Farfan-Ale JA, Loroño-Pino MA Garcia-Rejon J, Gomez-Carro S et al. Use of Google Earth to strengthen public health capacity and facilitate management of vector-borne diseases in resource-poor environments. Bull World Health Organ 2008;86:718-25. doi:10.2471/BLT.07.045880 PMID:18797648

7. Telles S, Singh N, Joshi M. Risk of posttraumatic stress disorder and depression in survivors of the floods in Bihar, India. Indian J Med Sci 2009;63:330-4. doi:10.4103/0019-5359.55883 PMID:19770523

8. Rahman A, Malik A, Sikander S, Roberts C, Creed F. Cognitive behaviour therapy-based intervention by community health workers for mothers with depression and their infants in rural Pakistan: a cluster-randomised controlled trial. Lancet 2008;372:902-9. doi:10.1016/S0140-6736(08)61400-2 PMID:18790313

9. Buse K, Walt G. Global public-private partnerships: part II - what are the health issues for global governance? Bull World Health Organ 2000;78:699_ 709. PMID:10859865 